Stable and Robust Design of Active Disturbance Rejection Current Controller for Permanent Magnet ! Machines in Transportation Systems

Ahmed M. Diab, Serhiy Bozhko, Michael Galea, Christopher Gerada

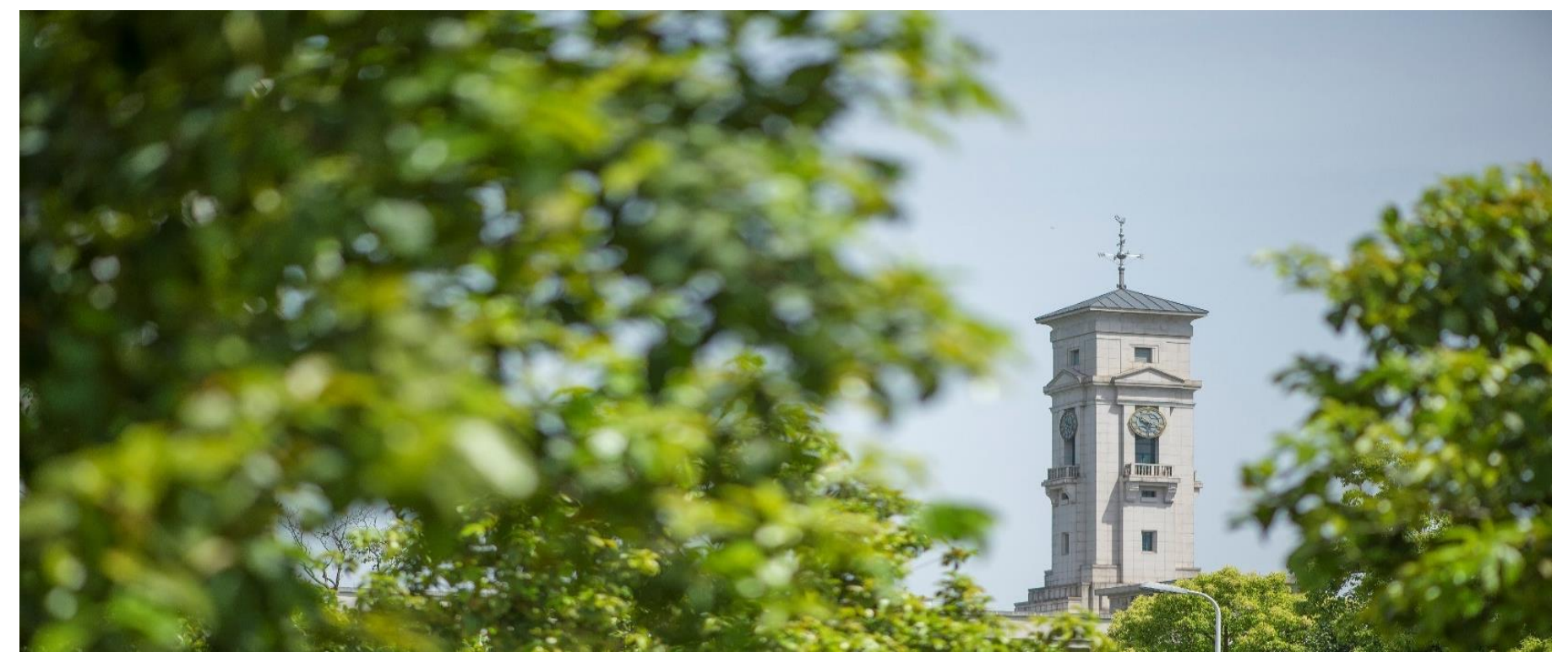


University of Nottingham Ningbo China, 199 Taikang East Road, Ningbo, 315100, Zhejiang, China.

First published 2020

This work is made available under the terms of the Creative Commons Attribution 4.0 International License:

http://creativecommons.org/licenses/by/4.0

The work is licenced to the University of Nottingham Ningbo China under the Global University Publication Licence:

https://www.nottingham.edu.cn/en/library/documents/researchsupport/global-university-publications-licence-2.0.pdf 


\title{
Stable and Robust Design of Active Disturbance Rejection Current Controller for Permanent Magnet Machines in Transportation Systems
}

\author{
Ahmed M. Diab, Serhiy Bozhko, Senior Member, IEEE, Michael Galea, Senior Member, IEEE, \\ Christopher Gerada, Senior Member, IEEE
}

\begin{abstract}
Active disturbance rejection control as a current control method for ac drive systems has been recently shown to have significant strengths. Its robustness to system uncertainties and its high disturbance rejection capability render it an attractive control scheme for various mobile applications. Until now however, all the known tuning methods, available in literature are based on a number of assumptions that may lead to the degraded drive performance and even to the loss of stability. This paper thus provides a rigorous analysis and proposes a new current control design method based on the active disturbance rejection control technique. The design derives a generic closed loop transfer function taking into account system delays and the dynamics of the extended state observer. Based on this analysis, a tuning method able to guarantee a set performance to avoid unstable operation is thus proposed. The effects of model uncertainties on the current loop system stability and robustness are also analyzed and reported. A tuning criterion to enhance system robustness and to improve its dynamic performance is developed and validated experimentally on a case study system.
\end{abstract}

Index Terms-Active disturbance rejection control, current control, variable drive system

\section{INTRODUCTION}

$\mathrm{T}$ HE electrification of transportation systems is the key trend towards reduction of fuel consumption and increasing efficiency [1]. Therefore, in aerospace area, the concept of the more and all electric aircrafts is adopted in many new programs and developments [2]. This trend encourages the aircraft industry to implement the electric drives in many systems such as the starter/generator and actuation systems [3, 4]. The Permanent Magnet Synchronous Machine (PMSM) is extremely attractive choice for these electric drive systems due to its excellent power density and high efficiency [5, 6], where these parameters have significant importance.

This work was supported in part by the Natural Science Foundation of China, through the project with code 51850410515 , and in part by the University of Nottingham's Propulsion Futures Beacon, through PF42. (Corresponding author: Ahmed M. Diab.). Ahmed M. Diab is with the Key Laboratory of More Electric Aircraft Technology of Zhejiang Province, University of Nottingham Ningbo China, Ningbo, China (e-mail: ahmed.diab@nottingham.edu.cn. Serhiy Bozhko and Michael Galea are with the Key Laboratory of More Electric Aircraft Technology of Zhejiang Province, University of Nottingham Ningbo China, Ningbo, China and Power Electronics, Machines and Control Group, University of Nottingham, Nottingham NG7 2RD, U.K. (Serhiy.bozhko@nottingham.ac.uk ; michael.galea@nottingham.edu.cn). Christopher Gerada is with Power Electronics, Machines and Control Group, University of Nottingham, Nottingham, NG7 2RD, UK. (e-mail: chris.gerada@ nottingham.ac.uk).
The excellent steady state and dynamic performance are also required. Therefore, high-performance PMSM control in the focus of comprehensive research during the last decades, and still continues to receive a great attention from the researchers.

The most established control strategy for PMSMs consists of cascaded control loops, typically with an inner loop for current regulation and an outer loop for speed control. It can be argued that the current control loop has a major effect on the overall system performance [7, 8]. Therefore, many studies that investigate various current control (CC) schemes are reported in [9-11] . In general, it can be stated that the field of CC is dominated by synchronous reference frame (SRF) proportionalintegral (PI) CCs. Their success is mainly due to the inherent simplicity in their design and implementation.

The main challenge with SRF PI CCs deals with the fact that their optimal operation depends heavily on the accurate knowledge of the machine parameters, required to design and tune the PI CCs correctly $[8,12,13]$. Any errors or uncertainties in machine parameters significantly affect the drive performance.

The challenge is that the machine parameters may significantly vary during the operation, especially in harsh environment such as in aircrafts. These parameters depends on various effects including temperature, pressure, load, saturation, cross saturation and operating frequencies [14, 15]. Manufacturing processes may introduce discrepancies in the machine parameters with respect to the nominal values [16]. It is therefore clear that all these internal disturbances, in addition to the external disturbances, can lead to degradations of a PMSM drive performance [3, 16, 17].

Currently, several methods to estimate and address disturbances are known. State observers (SO) and disturbance observers (DOB) have a long history of being used to overcome the effects of external disturbances $[16,18]$. Traditionally, these have been implemented to address the effects due to external disturbances, however a SO can also be used to estimate internal disturbances such as variations of machine parameters. An "extended state observer" (ESO) is proposed in [19] introducing active disturbance rejection control (ADRC). The basic idea of the ADRC is to consider uncertainties, unmodeled dynamics and external disturbances as a total disturbance which is estimated in real time by ESO. Then, an ESO-based feedback control is used to compensate the total disturbance and to keep the system output matching the 


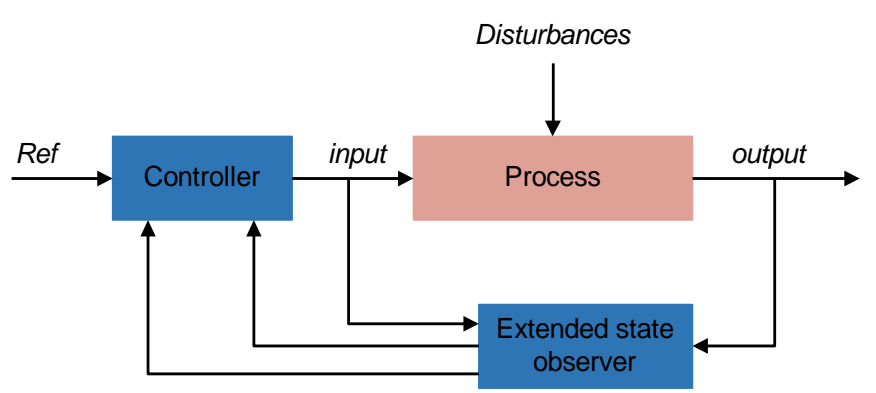

Fig. 1. Block diagram of the general structure of the ADRC scheme.

reference [19]. This basically means that a highly precise model of the machine isn't required anymore for control design, making the ESO an inherently simple scheme to implement as shown from the general structure of the ADRC in Fig. 1.

Considering all the above, it is attracting an interest as an alternative to the PI controller [18-20]. Hence, many researchers have addressed the ADRC scheme in different industrial applications, e.g. fly wheel energy storage system [20] , DC-DC converters [21, 22] and recently in motor drive systems. The implementation of ADRC in the current regulation of PMSM drive has been introduced into [18, 23-26] and superior performance compared to the PI current controller has been demonstrated. However, there are no detailed reports on selection of CC parameters when using the ADRC and in many cases the tuning is usually done by trial-and-error method [27-29]. Some basic guidelines are presented in [30, 31] using the bandwidth parameterization method [32]. It is based on specifying the controller and the observer bandwidth, however these are very applications specific for the work presented in $[30,31]$ and depend on assumptions that can actually only be applicable for that case only. In addition, these guidelines might have some limitations and can lead to unstable operation in practical systems due to unaccounted computational and modulation delays in the electric drives.

Stability and robustness are the key features for the electric drive systems in mobile applications such as the aircrafts [9]. Hence, the design procedure of the control system has to be reliable, simple and guarantee optimal dynamic performance. Therefore, this paper aims to develop an insight and to propose a reliable and simple methodology for the analysis and design of ADRC when implemented as CCs for a PMSM drive. The methodology proposed in this work utilizes a generic closed loop transfer function that results in an accurate representation of ADRC-based PMSM drive, including its stability map. This map generates a set of the CC gains for the ADRC that guarantee optimal performance and stability. In addition, a criterion to improve the $\mathrm{CC}$ robustness to cover wider range of the system uncertainties has been proposed. The innovative methodology is first introduced analytically, and then thoroughly investigated by simulations and further validated by the experimental results confirming the effectiveness of the developed concept.

\section{Current Control Based on ADRC}

This section deals with the theoretical concepts of the ADRC scheme. The required model of the controlled plant, i.e. machine, for ADRC implementation is developed, and the ESO and the feedback controller are designed.

The state space model of a PMSM machine [18] can be adopted as shown by (1) and (2), where $i_{d, q}, v_{d, q}, L_{d, q}$ and $d_{d, q}$, correspond to $d, q$ axis stator currents, voltages, inductances and external disturbances respectively. $r_{s}$ is the stator resistance, and $\omega_{r}$ is the electrical angular velocity. $\phi_{m}$ is the flux linkage of PMSM.

$$
\begin{gathered}
\frac{d i_{d}}{d t}=-\frac{r_{s}}{L_{d}} i_{d}+\omega_{r} \frac{L_{q}}{L_{d}} i_{q}-\frac{1}{L_{d}} d_{d}+\frac{1}{L_{d}} v_{d} \\
\frac{d i_{q}}{d t}=-\frac{r_{s}}{L_{q}} i_{q}-\omega_{r} \frac{L_{d}}{L_{q}} i_{d}-\frac{1}{L_{q}} \omega_{r} \phi_{m}-\frac{1}{L_{q}} d_{q}+\frac{1}{L_{q}} v_{q}
\end{gathered}
$$

Based on the ADRC principle [19], it is assumed that the external disturbances and the process dynamics are represented as a total disturbance. Subsequently, equations (1) and (2) can be re-written as (3) and (4), where $f_{d}$ and $f_{q}$ are calculated according to (5) and (6).

$$
\begin{gathered}
\frac{d i_{d}}{d t}=f_{d}+\frac{1}{L_{d}} v_{d} \\
\frac{d i_{q}}{d t}=f_{q}+\frac{1}{L_{q}} v_{q} \\
f_{d}=-\frac{r_{s}}{L_{d}} i_{d}+\omega_{r} \frac{L_{q}}{L_{d}} i_{q}-\frac{1}{L_{d}} d_{d} \\
f_{q}=-\frac{r_{s}}{L_{q}} i_{q}-\omega_{r} \frac{L_{d}}{L_{q}} i_{d}-\frac{1}{L_{q}} \omega_{r} \phi_{m}-\frac{1}{L_{q}} d_{q}
\end{gathered}
$$

Considering the above, it can be noted that from an ADRC perspective, the $d q$ model of the machine is the same for both axes. Therefore, only the $q$-axis model processing will be explained below.

\section{A. Extended State Observer Design}

The ESO of the $q$-axis current controller is designed based on the state space model given by (7), which is derived from (4) putting $u_{o}=v_{q}, b_{o}=1 / L_{q}$ and representing the $q$-axis by 2 states $\left(x_{1}=i_{q}, x_{2}=f_{q}\right)$. The total disturbance is represented by an extended state hence the system order increases by one.

$$
\left[\begin{array}{l}
\dot{x}_{1} \\
\dot{x}_{2}
\end{array}\right]=\left[\begin{array}{ll}
0 & 1 \\
& \\
0 & 0
\end{array}\right]\left[\begin{array}{l}
x_{1} \\
x_{2}
\end{array}\right]+\left[\begin{array}{ll}
b_{o} & 0 \\
0 &
\end{array}\right]\left[\begin{array}{l}
u_{o} \\
\dot{f}_{q}
\end{array}\right]
$$

From (7), it can be noticed that the ADRC principle simplifies the original system to a single integrator together with added total disturbance $f_{q}$, as can be clearly observed in Fig. 2. Subsequently, a $2^{\text {nd }}$ order linear extended state observer

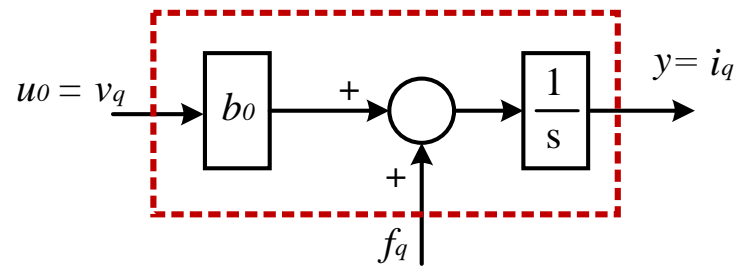

Fig. 2. Model of the $q$-axis winding of AC machine based on ADRC principle. 


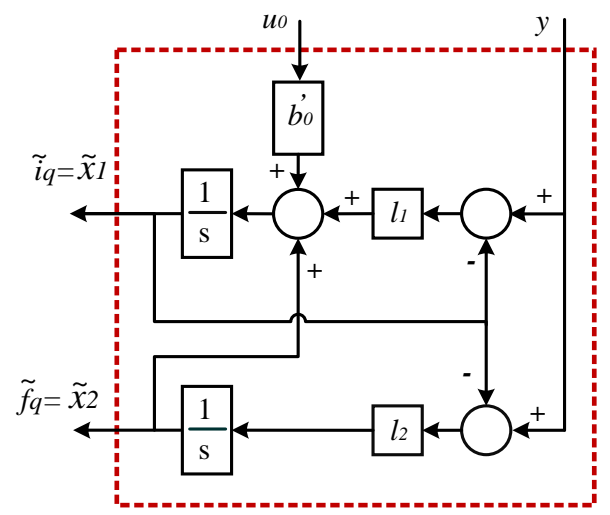

Fig. 3. Block diagrm of ESO in the current controller

(LESO) can be designed to estimate the total disturbance, as given by (8), where $b_{o}{ }^{\prime}=1 / L_{q}{ }^{\prime}, y$ is the machine current component in the q-axis, and $L_{q}{ }^{\prime}$ is the $q$-axis inductance used in the controller design which might be different than the actual value of the machine inductance $L_{q}$.

$$
\left[\begin{array}{c}
\tilde{x}_{1} \\
\tilde{x}_{2}
\end{array}\right]=\left[\begin{array}{ll}
0 & 1 \\
& \\
0 & 0
\end{array}\right]\left[\begin{array}{l}
\tilde{x}_{1} \\
\tilde{x}_{2}
\end{array}\right]+\left[\begin{array}{l}
b_{o}^{\prime} \\
0
\end{array}\right] u_{o}+\left[\begin{array}{c}
l_{1}\left(y-\tilde{x}_{1}\right) \\
l_{2}\left(y-\tilde{x}_{1}\right)
\end{array}\right]
$$

The target of any observer is to achieve fast and accurate convergence between the estimated and the actual states.

The observer gains are determined based on the desirable dynamics of the estimation error (9) which can be derived using (7) and (8) as shown by (10) where $l_{1}$ and $l_{2}$ are the observer gains.

$$
\begin{gathered}
\dot{e}=\dot{x}-\tilde{\dot{x}} \\
{\left[\begin{array}{c}
\dot{e}_{1} \\
\dot{e}_{2}
\end{array}\right]=\underbrace{\left[\begin{array}{ll}
-l_{1} & 1 \\
-l_{2} & 0
\end{array}\right]}_{\widetilde{\mathbf{A}}}\left[\begin{array}{l}
e_{1} \\
e_{2}
\end{array}\right]}
\end{gathered}
$$

To tune the observer gains, the pole placement method can be used [32]. This sets the location of the observer poles ( $S_{E S O I}$ and $S_{E S O 2}$ ) based on the design requirements formulated using natural damping frequency $\omega_{o}$ and damping ratio $\eta$, as shown by (11):

$$
\begin{aligned}
\Delta=|S I-\tilde{A}| & =\left(s-S_{E S O 1}\right)\left(s-S_{E S O 1}\right) \\
& =s^{2}+l_{1} s+l_{2}=s^{2}+2 \eta \omega_{o} s+\omega_{o}^{2}
\end{aligned}
$$

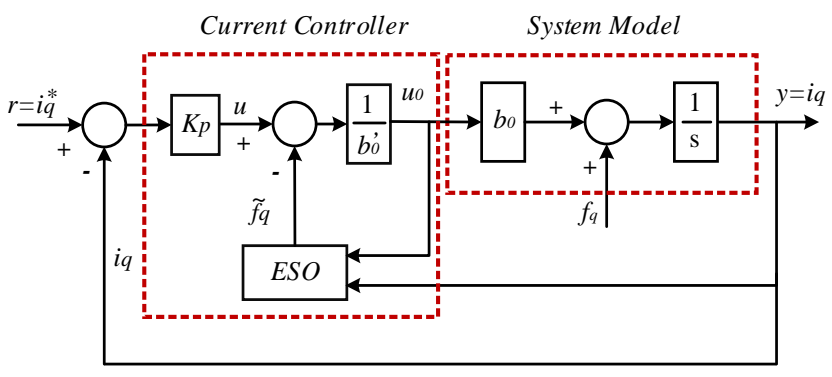

Fig. 4. Simplified Model of the current control loop for the AC machine based on ADRC principle
Typically, in Linear ADRC (LADRC), ESO poles are set to be equal $\left(s_{E S O 1}=s_{E S O 2}=\omega_{o}\right)[30,32]$. Consequently, the observer gains can then be chosen as shown in (12) where the damping ratio set at unity.

$$
\left.\begin{array}{l}
l_{1}=2 \omega_{o} \\
l_{2}=\omega_{o}^{2}
\end{array}\right\}
$$

Following from (12), the observer gains are tuned based on one parameter, namely $\omega_{o}$ that represents the observer bandwidth.

A block diagram of the ESO in the $q$-axis current controller is shown in Fig. 3. The ESO generates $\tilde{x}_{1}$ and $\tilde{x}_{2}$. These represent the estimated current and estimated lumped disturbance in the $q$-axis respectively. Subsequently, $\tilde{x}_{1}$ can be used for state feedback control however the actual value of the current $x_{1}$ is more easily achieved and therefore it is recommended to use $x_{1}$ whereas the parameter $\tilde{x}_{2}$ is responsible of the rejection of the lumped disturbance $f_{q}$ in the current control loop system as shown in Fig. 4.

\section{B. State Feed Back Controller}

For the CC, the feedback controller is designed based on the system output using the control law as expressed by (13), where $K_{p}$ is the state feedback controller, $r$ represents the system input which is consider in our case is the reference value of $q$-axis current and $u$ is the control signal generated from the feedback controller [33].

$$
u=K_{P}(r-y)
$$

From Fig. 4, (13) can be expressed as (14), considering the ability of the disturbance rejection where $u_{o}$ is the output of the current controller:

$$
u_{o}=\frac{1}{b_{o}^{\prime}}\left(K_{P}(r-y)-\tilde{f}_{\mathrm{q}}\right)
$$

From the above, one can conclude that the ADRC CC has two tuning gains, namely: the feedback controller gain $K_{P}$ and the observer bandwidth $\omega_{0}$. The conventional methods of tuning these gains are addressed in the following section showing the limitations and difficulties of these methods in the current control system design based on ADRC scheme.

\section{Conventional Tuning Methods}

In the conventional tuning methods, the closed loop transfer function of the current control loop can be derived from (14) taking into account (4) under the following assumptions [30, 31]:

- Exact rejection for the total disturbance has been achieved.

- The machine constant $b_{o}$ equals to the controller gain $b_{o}$ '.

$$
y=\frac{1}{s}\left[f_{q}+\frac{b_{o}}{b_{o}^{\prime}}\left(K_{P}(r-y)-\tilde{f}_{\mathrm{q}}\right)\right]=\frac{K_{P}}{s}(r-y)
$$

As a result of manipulation above, the closed loop transfer function of the ADRC-based CC can be expressed by (16): 


$$
y=r \frac{K_{P}}{s+K_{P}}
$$

The above equation shows that the system is simplified into a $1^{\text {st }}$ order one, and its bandwidth is $K_{P}$. Following recommendations given in $[30,31]$, the system tuning starts with the controller gain $K_{P}$ aiming to achieve a desired settling time. Then, the observer gains are tuned such that ESO poles are placed to the left of the closed-loop system poles to achieve the observer bandwidth $\omega_{o}$ which is chosen as a ratio $(m)$ between $3 \ldots 10$ times higher than $K_{P}$.

The previous tuning methods assumes that the ESO provides a perfect estimation and rejection for the total disturbances, which is not the case in most implementations due to the computational and modulation delays and coupling between the controller and observer dynamics (14). Hence, the selected ranges of the observer bandwidth may affect the system stability and deteriorate the overall system dynamics. Consequently, the overall system performance should be examined, and tuning criteria to be updated for realistic, nonideal ESO.

In addition, setting the state feedback controller $K_{P}$ depends on the desired settling time which has been determined in the previous publications according to the addressed specific only, without offering a systematic, generic technique [27, 28, 32]. This approach might lead the unstable current control as the desired settling time should be related to the switching frequency and the stability margins to guarantee good dynamics. These points are addressed in the following sections.

\section{Innovative Methodology to Analyze the Active DisTURBANCE REJECTION CURRENT CONTROLLER}

A generic closed loop transfer function is derived in this section. It provides an accurate representation of ADRC-based PMSM drive as the ESO dynamics and the delay model are taken in consideration. The disturbance rejection capability has been analyzed and evaluated compared to the conventional PI CC.

\section{A. Closed Loop Transfer Function of The Current Control System}

A generic closed loop transfer function of the ADRC CC system is derived using the block diagram in Fig. 5 where the ESO model is replaced by the modified model [34], in which the ESO is considered as consisting of two separate systems, as explained below.

The modified ESO model is derived from the original model (8) by re-writing it in the following form:

$$
\left[\begin{array}{l}
\tilde{x}_{1} \\
\tilde{\dot{x}}_{2}
\end{array}\right]=\left[\begin{array}{cc}
-l_{1} & 1 \\
-l_{2} & 0
\end{array}\right]\left[\begin{array}{l}
\tilde{x}_{1} \\
\tilde{x}_{2}
\end{array}\right]+\left[\begin{array}{cc}
b_{o}^{\prime} & l_{1} \\
0 & l_{2}
\end{array}\right]\left[\begin{array}{l}
u_{o} \\
y
\end{array}\right]
$$

The estimated states can be expressed in s-domain as follows:

$$
s\left[\begin{array}{c}
\tilde{X}_{1} \\
\tilde{X}_{2}
\end{array}\right]=\left[\begin{array}{cc}
-l_{1} & 1 \\
-l_{2} & 0
\end{array}\right]\left[\begin{array}{c}
\tilde{X}_{1} \\
\tilde{X}_{2}
\end{array}\right]+\left[\begin{array}{cc}
b_{o}^{\prime} & l_{1} \\
0 & l_{2}
\end{array}\right]\left[\begin{array}{l}
u_{o} \\
y
\end{array}\right]
$$

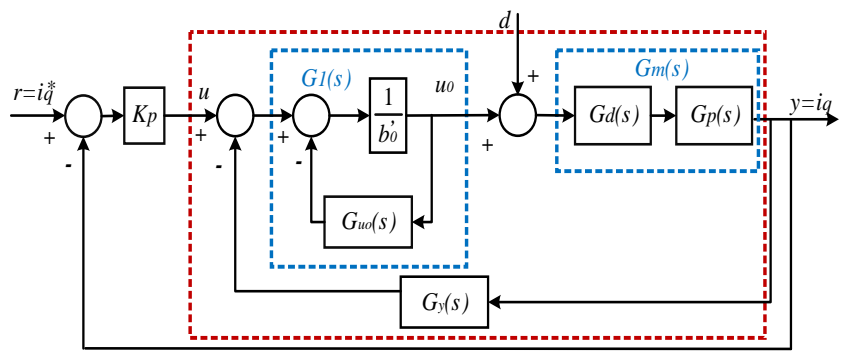

Fig. 5. Block diagram of the current control loop based on ADRC using the modified ESO model

$$
\begin{aligned}
& \therefore \tilde{X}_{1}=\frac{b_{o}^{\prime} s}{s^{2}+l_{1} s+l_{2}} U_{o}+\frac{l_{1} s+l_{2}}{s^{2}+l_{1} s+l_{2}} Y \\
& \therefore \tilde{X}_{2}=\frac{-b_{o}^{\prime} l_{2}}{s^{2}+l_{1} s+l_{2}} U_{o}+\frac{l_{2} s}{s^{2}+l_{1} s+l_{2}} Y
\end{aligned}
$$

Based on (20), the estimated total disturbance $\left(\tilde{X}_{2}\right)$ can be split in to two separate systems $G_{u о}(s)$ and $G_{y}(s)$ as given in (21) and (22), respectively.

$$
\begin{aligned}
& G_{u o}(\mathrm{~s})=\frac{-b_{o}^{\prime} l_{2}}{s^{2}+l_{1} s+l_{2}} \\
& G_{y}(\mathrm{~s})=\frac{l_{2} s}{s^{2}+l_{1} s+l_{2}}
\end{aligned}
$$

The delay function $G_{d}(s)$ in Fig. 5 includes the advance angle in order to mitigate the delay in the synchronous rotating reference frame positioning definition [35]. This delay can be modeled by the $2^{\text {nd }}$ order Pade approximation, given in (23). where $T_{d}$ is the time delay due to the inverter and digital controller which is evaluated by 1.5 sampling time [8].

$$
G_{d}(s)=\frac{1-\frac{T_{d}}{2} s+\frac{T_{d}^{2}}{12} s^{2}}{1+\frac{T_{d}}{2} s+\frac{T_{d}^{2}}{12} s^{2}}
$$

Subsequently, the open- and closed-loop transfer functions of the block diagram Fig. 5 can be described by (24) and (26), respectively considering the external disturbance $d$ equal zero.

$$
\begin{array}{r}
G_{o . l}(s)=K_{P} \frac{G_{1} G_{m}}{1+G_{1} G_{m} G_{y}} \\
G_{p}(s)=\frac{1}{L s+r_{s}}
\end{array}
$$

$G_{m}(s)$ in (24) represents a combination of the machine model $G_{p}(s)$ and the delay model $G_{d}(s)$, where $L$ represent a generic symbol for the machine inductance in $d$ or $q$ axis.

$$
G_{c . l}(s)=\frac{\left(s^{2}+l_{1} s+l_{2}\right)\left(B_{2} s^{2}+B_{1} s+B_{0}\right)}{A_{5} s^{5}+A_{4} s^{4}+A_{3} s^{3}+A_{2} s^{2}+A_{1} s+A_{0}}
$$

where

$$
\begin{aligned}
& A_{5}=\frac{T_{d}^{2} b_{o}^{\prime} L}{12}, \quad A_{4}=\frac{T_{d}^{2}}{12}\left(b_{o}^{\prime} r_{s}+b_{o}^{\prime} L l_{1}+K_{p}\right)+0.5 T_{d} b_{o}^{\prime} L \\
& A_{3}=b_{o}^{\prime} L+0.5 T_{d}\left(b_{o}^{\prime} r_{s}+b_{o}^{\prime} L l_{1}-K_{p}\right)+\frac{T_{d}^{2}}{12}\left(b_{o}^{\prime} r_{s} l_{1}+l_{2}+K_{p} l_{1}\right) \\
& A_{2}=\left(b_{o}^{\prime} r_{s}+b_{o}^{\prime} L l_{1}+K_{p}\right)+0.5 T_{d}\left(b_{o}^{\prime} r_{s} l_{1}-l_{2}-K_{p} l_{1}\right)+K_{p} \frac{T_{d}^{2} l_{2}}{12}
\end{aligned}
$$


$A_{1}=b_{o}^{\prime} r_{s} l_{1}+l_{2}+K_{p} l_{1}-0.5 l_{2} K_{p} T_{d} \quad, A_{0}=K_{p} l_{2}$

$B_{2}=\frac{T_{d}^{2}}{12} K_{p} \quad, \quad B_{1}=-0.5 K_{p} T_{d}, \quad B_{0}=K_{p}$

Equation (26) is a generic closed loop transfer function for the current control loop based on the ADRC scheme which is used for the subsequent analysis in Section (V). From (26) one can perceive that the system stability can be studied through the analysis of characteristic equation:

$$
A_{5} s^{5}+A_{4} s^{4}+A_{3} s^{3}+A_{2} s^{2}+A_{1} s+A_{0}=0
$$

\section{B. Disturbance Rejection Capability Analysis}

The disturbance rejection capability is considered the main advantage of the ADRC scheme compared to the conventional PI controller which is addressed in this section.

Analysis of the disturbance rejection capability can be performed based on the transfer function between the external disturbance $d$ as input and the output current using (28) derived from Fig. 5.

$$
G_{d 1}(s)=\left.\frac{i_{q}}{d}\right|_{i_{q}^{*}=0}=\frac{G_{m}}{1+K_{p} G_{1} G_{m}+G_{y} G_{1} G_{m}}
$$

To analyze the disturbance rejection capability of the ADRC scheme in the current control loop compared to the conventional PI, the disturbance rejection transfer function is determined for the conventional PI controller in the current control system shown in Fig.6 and reported in (29) where $P$ and $I$ are the controller gains.

$$
G_{d 2}(s)=\left.\frac{i_{q}}{d}\right|_{i_{q}^{*}=0}=\frac{G_{m}}{1+G_{\mathrm{PI}} G_{m}}
$$

where $G_{\mathrm{PI}}=\frac{P s+\mathrm{I}}{\mathrm{s}}$

Considering the PMSM defined by Table I which is used as a starter/generator in aircraft applications [4], the frequency response of (28) and (29) are shown in Fig.7 which demonstrates the ability of the ADRC scheme to provide better disturbance rejection capability than the conventional PI.

In the following section, a proposed tuning method are presented to guarantee the current control system stability and the dynamic performance.

\section{Proposed Tuning Method Based on Stability MaP}

The system's analysis can be performed based on (27), including construction of the proposed stability map using the proposed flowchart in Fig. 8. The values of $m$ and $K_{P}$ are required for this purpose. For the selected range of $K_{P}$ (which refers to the current control loop bandwidth), it is proposed to

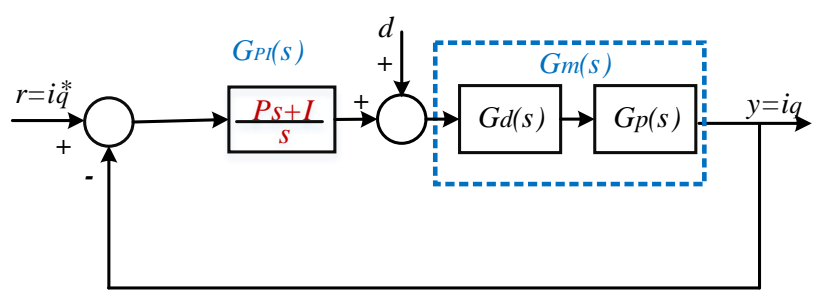

Fig. 6 Current control loop based on the conventional PI controller

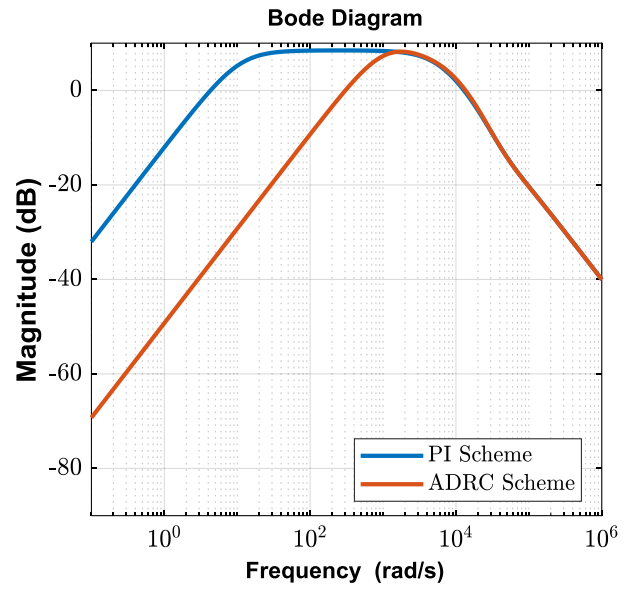

Fig. 7 Freqeuncy responcse analysis of the disturbance rejection capability got PI and ADRC schemes

set its initial value $\left(K_{P i}\right)$ at 10 . As mentioned, $K_{P}$ refers to the system bandwidth so lower setting for its initial value is unused in the practice which makes 10 is accepted for $K_{P i}$. For the final value $\left(K_{P f}\right)$, it is proposed to be chosen using the root locus of (30). It represents the open loop transfer function of Fig. 4 considering the assumptions in Section III. So, it describes the system dynamics in the ideal case when the ESO model is neglected.

$$
G_{o}(s)=\frac{K_{P}}{s} G_{d}(s)
$$

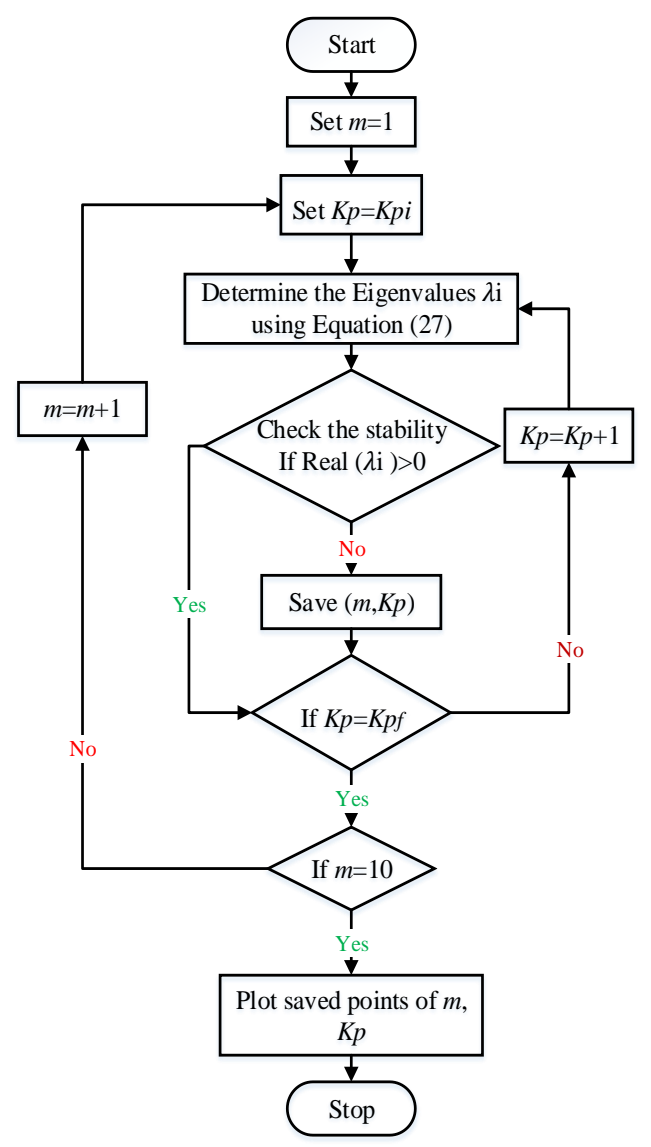

Fig. 8. General flowchart to construct the stability map of the CC gains 


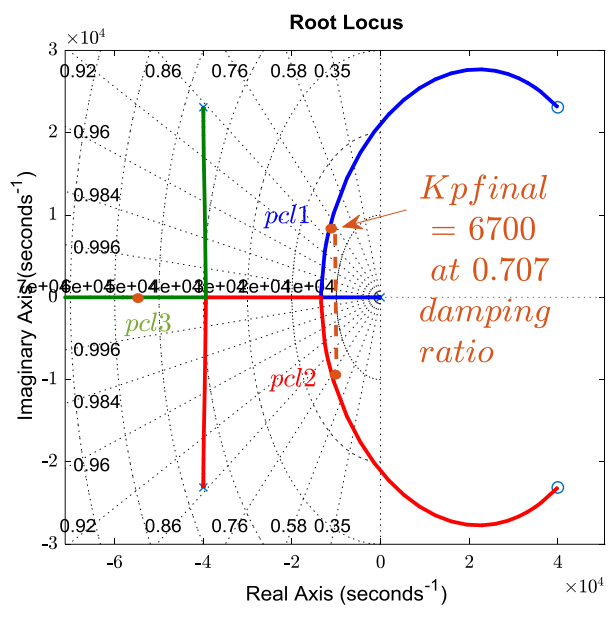

Fig. 9 Root locus of (30) at $20 \mathrm{kHz}$ switching frequency

Fig. 9 shows the root locus of (30) at $20 \mathrm{kHz}$ switching frequency $\left(f_{s w}\right)$ as an example, it can be shown that closed loop system poles $\left(p_{c l}\right.$ and $\left.p_{c 2}\right)$ moves to the imaginary axis referring to lower damping ratio when the value of $K_{P}$ increases. Therefore, it is proposed to choose the value of $K_{P f}$ such that to achieve an optimal damping ratio with strongest disturbance rejection and with no overshoot ( $\eta_{\text {opt }}=0.707$ ) [36]. It should be mentioned that this value is chosen for ideal system, therefore, in an actual system, the damping ratio for the selected $K_{P f}$ will be lower due to the effect of ESO dynamics. Consequently, $K_{P f}$ can be defined by the maximum acceptable limit of $K_{P}$ that corresponds to 0.707 damping ratio in the ideal case. A general formula for $K_{P f}$ can be derived as a function of the switching frequency as shown below.

The closed loop characteristics equation of the ideal system defined by (30) can be derived as follows:

$$
T_{d}^{2} s^{3}+\left(6 T_{d}+K_{p} T_{d}^{2}\right) s^{2}+\left(12-6 K_{p} T_{d}\right) s+12 K_{p}=0
$$

The generic expression of the closed loop poles of (31) can be seen in the Appendix. As $K_{P f}$ is selected to achieve 0.707 damping ratio, this mean that the real and imaginary of the conjugate poles $\left(p_{c l}\right.$ and $p_{c 2}$ ) are equal. So, a generic formula for $K_{P f}$ can be derived as given in (32).

$$
K_{p f} \cong 0.335 f_{s w}
$$

For the selected range of $m$, it can be fixed from 1 to 10 . Accordingly, the flowchart can be valid for any electric drive system as it depends only on the switching frequency of the drive system and the machine resistance and inductance values.

Having determined the suitable range of these two gains, a stability map can be constructed to relate them to the operational regions to ensure a stable control scheme, as detailed below.

The proposed stability map can also be used assess the system robustness towards the machine parameters variation and also to guarantee a good dynamic performance. This concept will be illustrated by the case study considering the PMSM defined by Table I. The stability map based on the

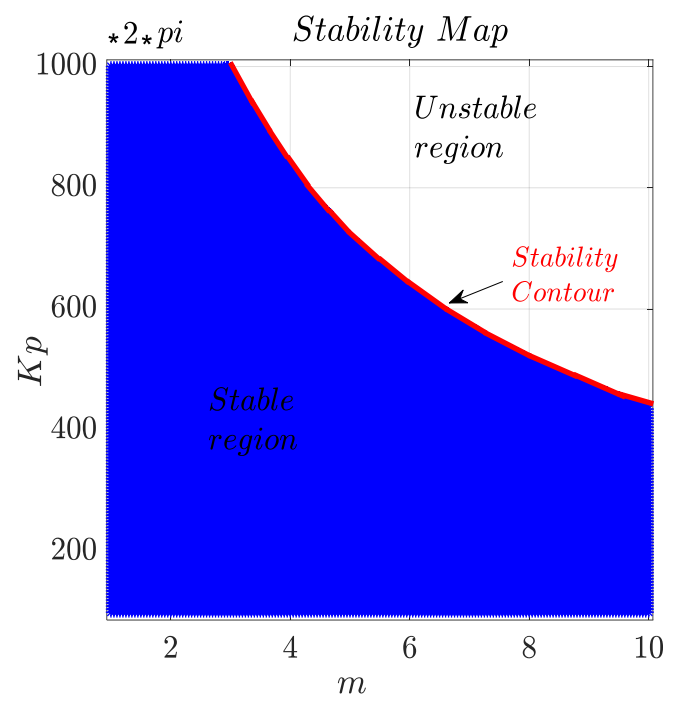

Fig. 10 Stability map of the current controller gains at $f_{s w}=20 \mathrm{kHz}$

TABLE I: MACHINE PARAMETERS

\begin{tabular}{l|c|c}
\hline \hline Parameter & SYMBOL & Value \\
\hline Phase Resistance & $r_{s}$ & $1.058 \mathrm{~m} \Omega$ \\
\hline Phase Inductance & $L_{d}=L_{q}=L$ & $99 \mu \mathrm{H}$ \\
\hline Poles pairs & $p$ & 3 \\
\hline Magnet flux linkage & $\Phi_{m}$ & $0.03644 \mathrm{wb}$ \\
\hline Rated Power & $\mathrm{P}_{\text {rated }}$ & $45 \mathrm{kw}$ \\
\hline Switching Freqeuncy & $f_{s w}$ & $20 \mathrm{kHZ}$ \\
\hline
\end{tabular}

proposed ADRC CC has been calculated as described above and is shown in Fig. 10. The blue area marked as 'stable region' represents the acceptable range for the $\mathrm{CC}$ gains whereas the white area indicates where the system becomes unstable, for example - if the gains are chosen following the conventional methods.

The stability map of Fig. 10 sets a contour for the gains that guarantee the system stability. However, it is not enough in practice to ensure the system is stable. There must be some stability margins to provide acceptable dynamic performance which is one of the key targets through the current control system design. Phase and gain margins can be used as an indicator of the transient performance[37]. These can be determined from the analysis of the open loop transfer function in the frequency domain using (24). The phase and gain margins that correspond to the stable region of stability map are shown in Fig. 11 and Fig. 12, respectively.

It can be observed that further limitations should be set on the stable region to guarantee acceptable transient performance which is corresponding to around $50^{\circ}$ as a phase margin and 6 $\mathrm{dB}$ as a gain margin $[37,38]$. Consequently, the choice of the controller gains should not only be under the stability contour but also below the performance contour shown in Fig. 13 to guarantee a good dynamic performance. This performance contour can be evaluated based on the intersection between the acceptable gain margin and the surface of the determined gain margins shown by Fig. 12 . 


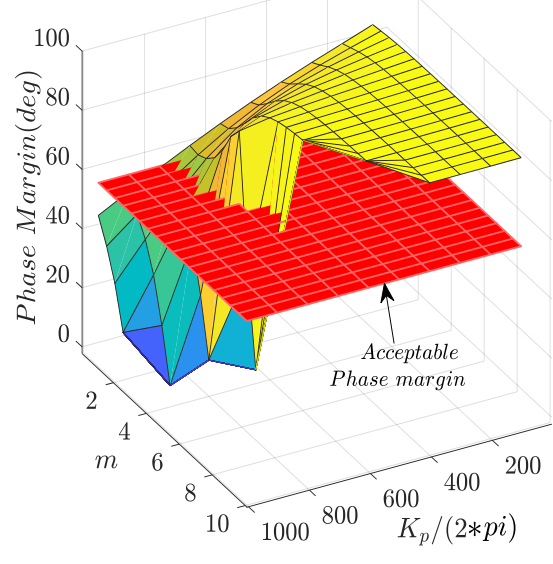

Fig. 11 Phase margins of the CC system using the stable region

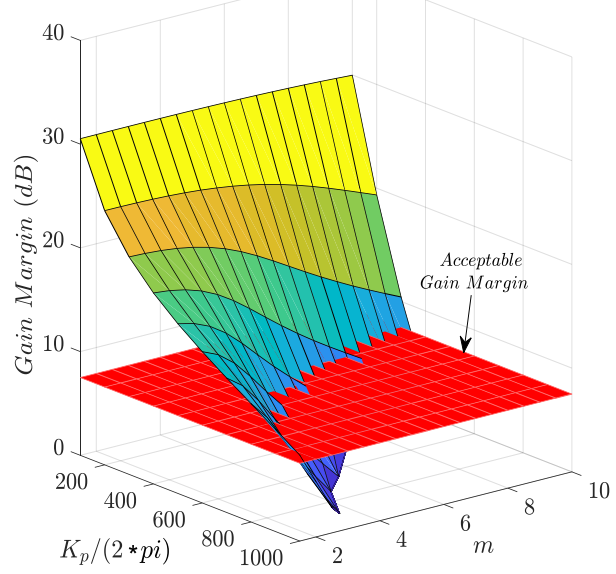

Fig. 12 Gain margins of the CC system using the stable region

The dynamic behavior of the designed CC can also be tested by analyzing the transient response of equation (26). For example, different settings are chosen from the stability map

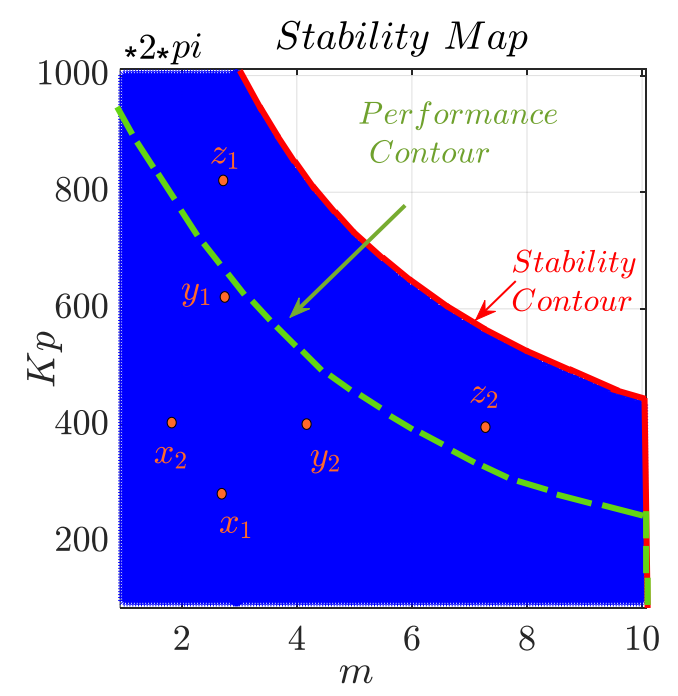

Fig. 13 Stability map of the current controller gains at $f_{s w}=20 \mathrm{kHz}$ considering the dynamic performance during the design
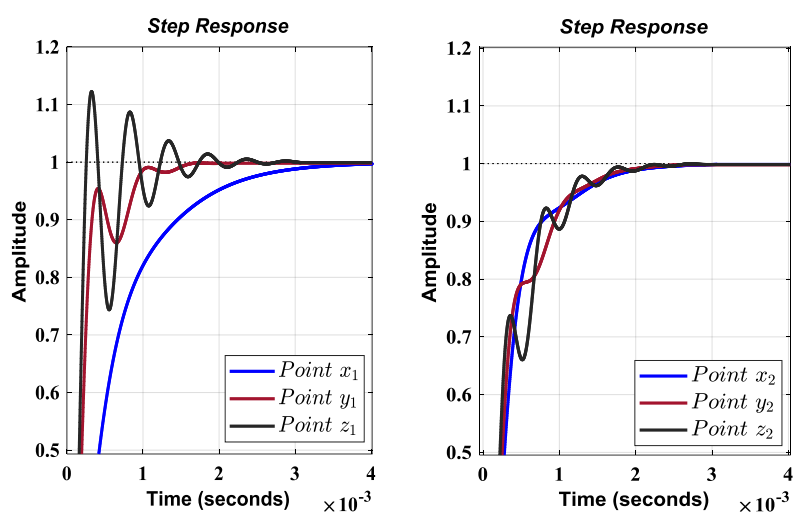

Fig. 14 Step responcse of equation (26) fordifferent CC settings

TABLE II: CC SETTING FOR TRANSIENT ANALYSIS

\begin{tabular}{l|c|c|c|c|c|c}
\hline \hline & Point $\mathrm{x}_{1}$ & Point $\mathrm{y}_{1}$ & Point $\mathrm{z}_{1}$ & Point $\mathrm{x}_{2}$ & Point $\mathrm{y}_{2}$ & Point $\mathrm{z}_{2}$ \\
\hline$m$ & 2.7 & 2.7 & 2.7 & 2 & 4.3 & 7.5 \\
\hline$K_{P}$ & $500 \pi$ & $1200 \pi$ & $1600 \pi$ & $800 \pi$ & $800 \pi$ & $800 \pi$ \\
\hline
\end{tabular}

shown by Fig. 13 and listed in Table II. Step responses corresponding to these controller sets are shown in Fig. 14 in order to analyze the dynamic performance of the $\mathrm{CC}$ and provide a good understanding for the stability map. It can be observed from Fig. 14 that the dynamic behavior deteriorates producing more oscillations once the controller's setting crosses the performance contour and becomes close to the stability contour. It can be also noted that higher $K_{P}$ values refers to higher bandwidth and faster dynamics, but the system bandwidth is limited because of the existing delay. Moreover, the increasing value of $m$ refers to higher ESO bandwidth. Hence, faster disturbance rejection can be guaranteed. However, it is observed that the system stability deteriorates when the value of $m$ increases. This limitation of the ESO gains can be interpreted by the coupling in the dynamics between the ESO and the controller gain $K_{P}$ which is affected by the delay.

The discussion above provides better understanding of the stability map and how it can provide tuning the $\mathrm{CC}$ gains of the ADRC scheme. To conclude the above, it can be stated that the good choice of $K_{P}$ and $m$ should provide required CC dynamics in terms of the transient response with the ability of disturbance rejection. Therefore, it is advised to choose them based on the proposed stability map beyond the performance contour. In addition, the dynamic performance can be tested by measuring the stability margins using equation (24) or transient response from equation (26).

\section{ROBUSTNESS TO MODEL UNCERTAINTIES}

The machine parameters can change during its operation due to many factors. Moreover, the parameters used for CC design typically are not much accurate. These uncertainties affect the system performance, including its stability conditions. Thus, the effects of these uncertainties on the CC performance are studied in this section through the analysis of the system eigenvalues migration. For this study, an initial set of the 


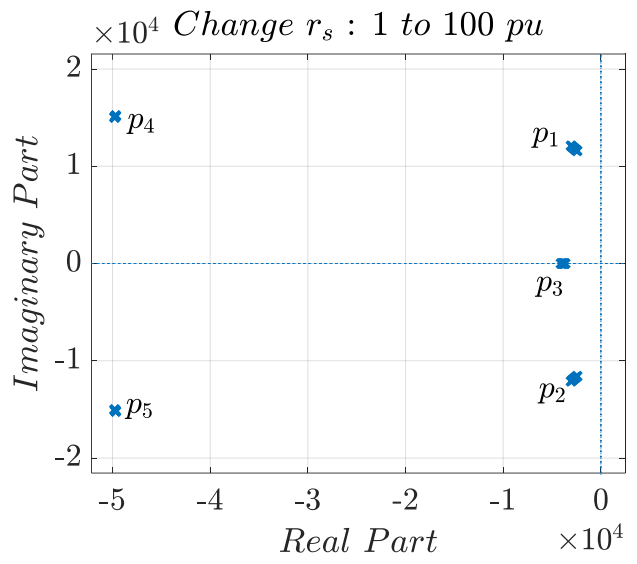

Fig. 15 Migration of the eigenvalues at different values of machine's resistance

observer and the controller gains is required. These values can be taken from the map in Fig. 13, and for this study case $K_{P}$ $=1200 \pi$ and $m=3$ are set. Correspondingly, the observer gains are defined as follows:

$$
\begin{aligned}
& \therefore \omega_{o}=m K_{P}=11309.73 \\
& l_{1 o}=22620, l_{2 o}=128 * 10^{6}
\end{aligned}
$$

For changes in the machine resistance, the migration of the $\mathrm{CC}$ eigenvalues is shown in Fig. 15: One can conclude that these do not move significantly for the wide range of the machine resistance (1pu to $100 p u$ range has been analysed). So, the change of the machine resistance has almost no effect on the ADRC CC performance.

For the inductance changes, as it can be observed from Fig.16 that the dominant system poles (indicated as $p_{1}, p_{2}$ and $p_{3}$ ) move towards the unstable area with the decrease of the inductance. Hence, the system dynamics deteriorates up to instability that occurs when inductance drops to $0.7 \mathrm{pu}$ in the studied case. Hence, the sensitivity of the CC to the inductance variation is significant and for such practical cases should be duly addressed.

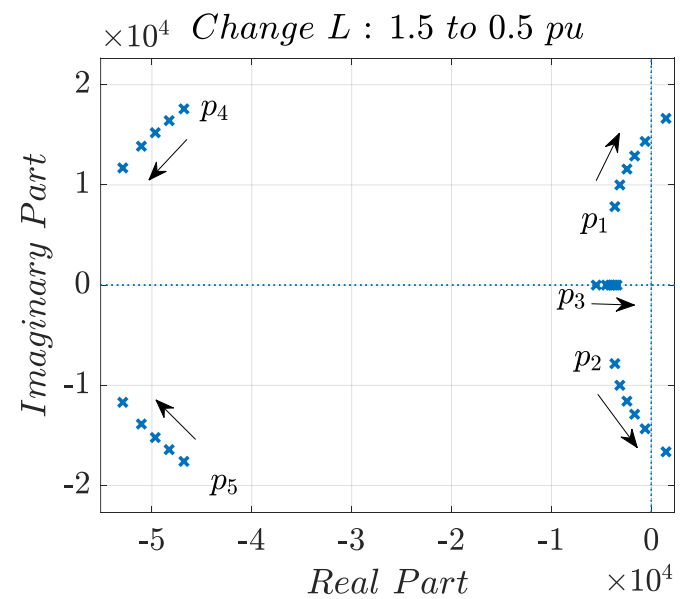

Fig. 16 Migration of the eigenvalues at different values of machine's inductance

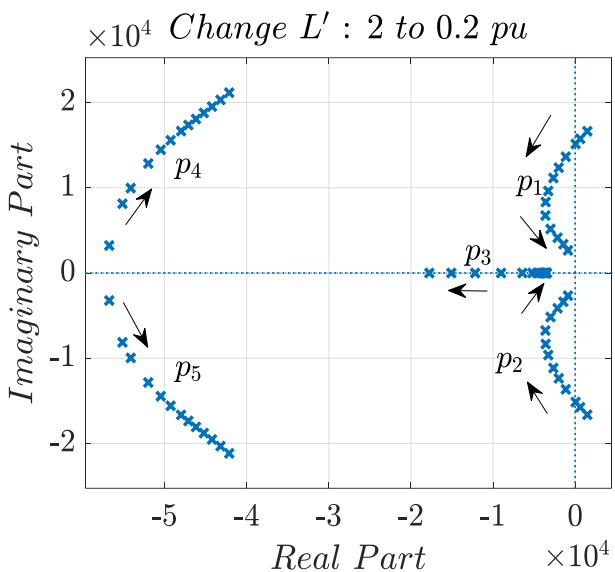

Fig. 17 Migration of the eigenvalues at different sets of the inductance value used in the controller

The uncertainty of the inductance value used in the controller design to set the gain $b_{o}^{\prime}$ has to be considered because the accurate value of the machine inductance $L$ is often unavailable. Therefore, the robustness of the system to the machine inductance value needs to be tested. For this purpose, the migration of the system eigenvalues is analysed as shown in Fig. 17, where the inductance value used to define the controller parameter $b_{o}^{\prime}$ changes from $2 p u$ to $0.2 p u$. As it is seen, setting the inductance in the controller $L^{\prime}$ larger than actual machine' inductance $L$ moves $p_{1}$ and $p_{2}$ towards the unstable area thus degrading the system stability. Contrary, decrease of $L^{\prime}$ moves the system eigenvalues towards more stable areas enhancing the system stability.

It can be observed that the eigenvalues are most remote from the imaginary axis when $L^{\prime}$ is in the range $0.45 \ldots 0.7 p u$. To note, at $L^{\prime}<0.45 \mathrm{pu}$ the eigenvalues start to move towards the imaginary axis again.

Setting the gain $b_{o}^{\prime}$ at higher values to enhance the controller dynamics has been addressed in [28] as a general rule observed from simulation results without any analysis to support the idea compared to this study which addresses this property from the analytical results. Moreover, It is advised in [28] to set the parameter $b_{o}^{\prime}$ to have a higher value than its actual which refers to lower inductance in the current loop system. However, it is noticed that reducing the value of $L^{\prime}$ should be limited as observed from the eigenvalues study in Fig. 17.

The conclusion of this analysis is that there is a significant impact of $L^{\prime}$ on the ADRC CC stability and robustness, therefore the following Section considers the ways to enhance the loop performance under such conditions.

\section{RETUNING THE CONTROLLER GAINS FOR BETTER ROBUSTNESS}

As discussed above, the value of $L^{\prime}$ has a significant effect on the location of the system eigenvalues defining the CC performance, stability conditions and the maximum range of the system parameters variation to keep the system stable.

As mentioned in Section VI, setting $L^{\prime}$ within the range $0.45 \ldots 0.7 p u$ improves the system robustness which can be shown in Fig.18. It shows the eigenvalues migration when the machine inductance changes from 2 to 0.5 pu where the value 


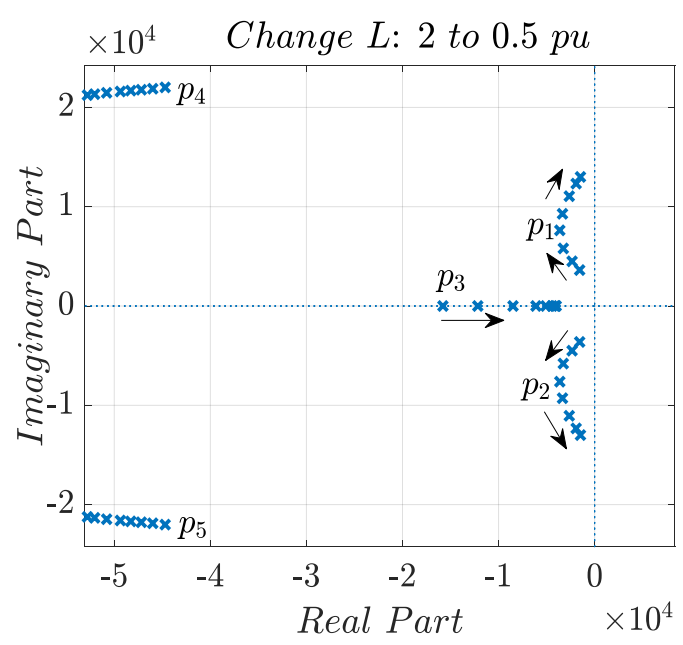

Fig. 18 Migration of the eigenvalues at different sets of the machine inductance at $L^{\prime}=0.6 p u$

of $L^{\prime}$ is selected to be $0.6 p u$. Compared to Fig. 16, the current loop is stable within the same range of the machine inductance variation. This reflects the effect of $L$ ' on the improvement of the system robustness. Consequently, it is recommended to choose the observer gains based on the stability map whereas the enhancement of the system robustness can be achieved only by reduction of the value of $L^{\prime}$.

One can also recommend to reduce $L^{\prime}$ to be within $0.5 \mathrm{pu}$ to $0.7 p u$ of the nominal value of the machine inductance $L$. This ratio can achieve better robustness even with a wide variation of the machine inductance (this can reach $35 \%$ in machines such as the synchronous reluctance or IPM according to studies [39, 40]. The range of $L$ ' setting can also cover the error which may happen when $L^{\prime}$ is set in the controller if the datasheet machine inductance is higher than the actual one.

Another effect that needs to be discussed for setting the value of $L$ ' during the CC tuning using stability map. As discussed in Section V, the stability map is established using the exact value of the machine inductance to set $L^{\prime}$. But, if there is an error in the inductance value $L^{\prime}$, the stability map is going to change.

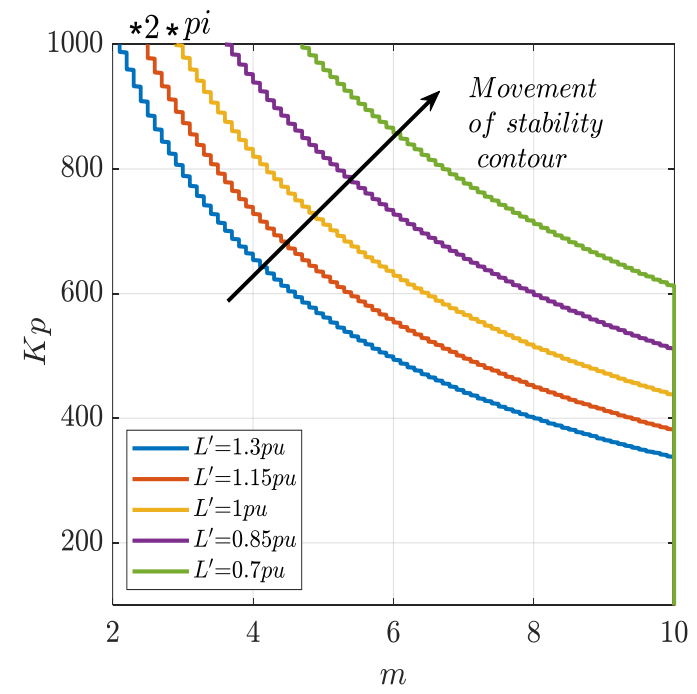

Fig. 19 Migration of stability map at different values of $\mathrm{L}^{\prime}$ at $\mathrm{fs}=20 \mathrm{kHz}$

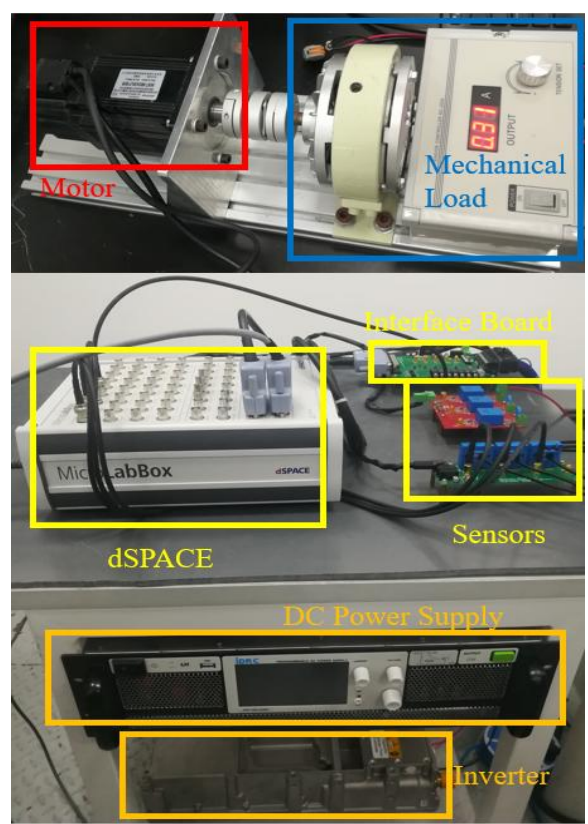

Fig. 20 Expermintal test rig

TABLE III: TeSted MAchine PARAMETERS

\begin{tabular}{l|c|l}
\hline \hline Parameter & SYMBOL & Value \\
\hline Phase Resistance & $r_{s}$ & $1.1 \Omega$ \\
\hline Phase Inductance & $L_{d}=L_{q}=L$ & $7.145 \mathrm{mH}$ \\
\hline Poles pairs & $p$ & 4 \\
\hline Magnet flux linkage & $\Phi_{m}$ & $0.0228 \mathrm{wb}$ \\
\hline Rated Power & $\mathrm{P}_{\text {rated }}$ & $0.75 \mathrm{~kW}$ \\
\hline Switching Freqeuncy & $f_{S W}$ & $10 \mathrm{kHZ}$ \\
\hline
\end{tabular}

This change can be observed from Fig. 19: if $L^{\prime}$ has lower set than $L$, the stable region enlarges to cover wider range of $K_{P}$ and $m$. This will allow for the current loop to operate at higher bandwidth by setting higher gains of the controller and the observer. It can be also deduced that the $\mathrm{CC}$ gains can be tuned using the stability map constructed for lower $L^{\prime}$ (around 0.7$0.85 \mathrm{pu}$ ). Such tuning approach can be recommended for the $\mathrm{AC}$ drives that have less uncertainty in machine inductance, such as surface mounted PMSM, in order to achieve higher bandwidth and better observation accuracy.

\section{CASE STUdy}

The effectiveness of the proposed design criterion has been verified by both simulations and experiments. The main data of the PMSM used for the lab tests and details of the experimental test rig are given in Table III. The test rig is shown in Fig. 20. The control algorithms are implemented on dSPACE MicroLabBox Hardware. The machine is linked to a dynamometer to set a required mechanical loading. The controller gains have been tuned using the stability map of the tested drive system shown in Fig. 21. Five settings for the controller gains have been chosen as recorded in Table IV to validate the proposed methodology of ADRC CC tuning and to verify the theoretical results of the previous sections. 


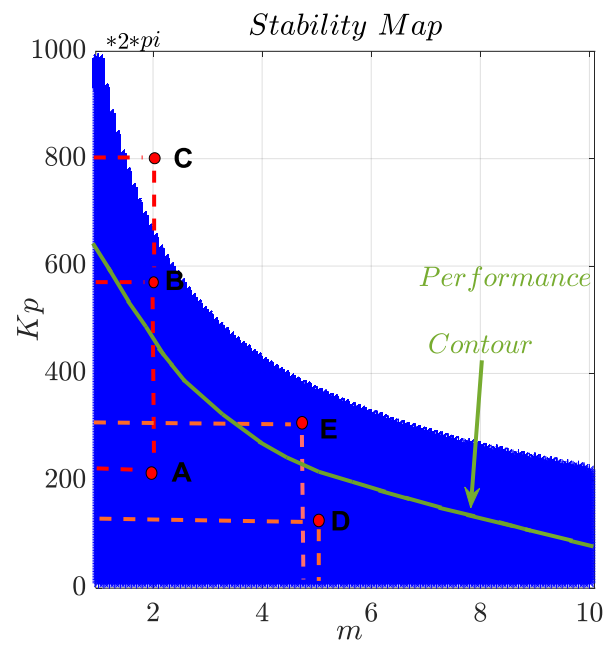

Fig. 21 Stability Map for tested motor at $f_{s w}=10 \mathrm{kHz}$

\begin{tabular}{l|c|c|c|c|c}
\multicolumn{5}{c}{ TABLE IV: CC SETTINGS FOR CASE STUDY } \\
\hline \hline & Point A & Point B & Point C & Point D & Point E \\
\hline$m$ & 2 & 2 & 2 & 4.7 & 4.3 \\
\hline$K_{P}$ & $430 \pi$ & $1160 \pi$ & $1600 \pi$ & $220 \pi$ & $560 \pi$ \\
\hline
\end{tabular}

\section{A. Normal Operation}

In Fig. 22, the CC based on ADRC is tested by application different mechanical loads when the machine is running at 1500 rpm. The CC gains are chosen from the stability map Fig. 21, according to the point A. As seen from Fig. 22, the CC based on ADRC can provide good and fast processing for the sudden load changes.

The disturbance rejection capability has been tested for both schemes (ADRC and PI) during the experiments by applying step voltage $=7 \mathrm{v}$ at $\mathrm{t}=2.55 \mathrm{sec}$ to the output voltage signal in the q-axis from the controller when the motor runs at $1500 \mathrm{rpm}$. The results are shown in Fig.23 to verify the analytical study in Section (IV) that the ADRC provide better disturbance rejection than the conventional PI.

\section{B. Stability Map Verification}

The different sets for the CC gains are chosen from the stability map to represent stable, marginally stable and unstable system behaviour mentioned in Table IV. As the decoupled current dynamics for $d$ - and $q$-current is identical, the $d$-current reference step from $i^{*}{ }_{d}=1 \mathrm{~A}$ to $i^{*}{ }_{d}=4 \mathrm{~A}$ at stand-still has been applied to validate the proposed $\mathrm{CC}$ design criterion whilst

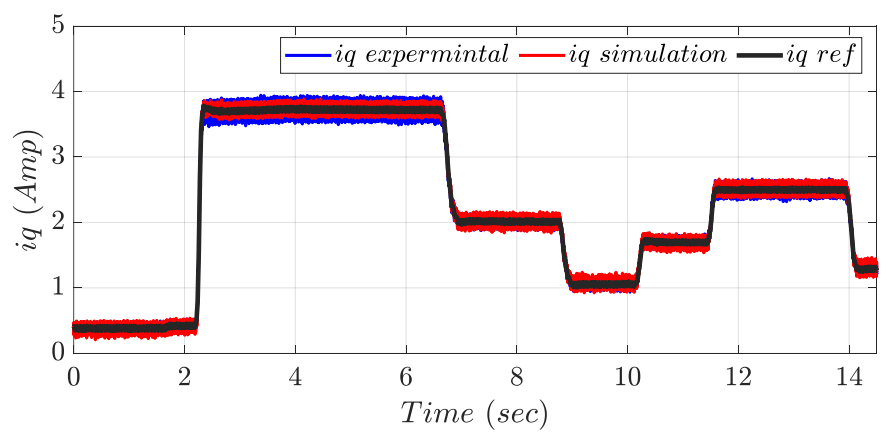

Fig. 22. Results of normal nneration using CC. hased on ADRC. N=1500 rnm
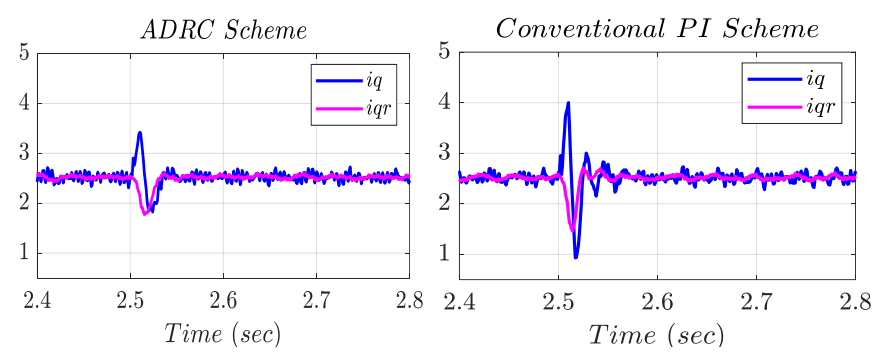

Fig. 23 Expermintal results for the current responcse during the disturbance for the conventional PI and the ADRC schemes

avoiding unwanted torque effects. The rotor was locked to provide similar initial conditions for all test cases.

It can be clearly seen from the results of the step response shown from Fig. 24 to Fig. 26 that the transient response at points $\mathrm{B}$ and $\mathrm{E}$ is more oscillatory than at points $\mathrm{A}$ and $\mathrm{D}$. This indicates a degradation of the system stability margins and corresponds to the analytically expected results from the stability map. The results also show that the performance contour guarantees the dynamic performance of the current control system. Accordingly, setting the controller gains should be a way form the stability contour and below the performance contour to avoid low stability margins shown by the oscillatory response for the points $\mathrm{B}$ and $\mathrm{E}$. These results match the step response analysis of equation (26) shown in Section (V). If the gains are set at the point $\mathrm{C}$, the system, as predicted, loses its ability to process the reference since it becomes unstable (as shown in Fig. 26).

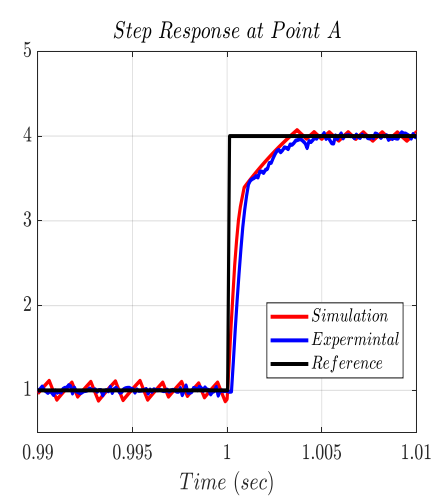

(a)

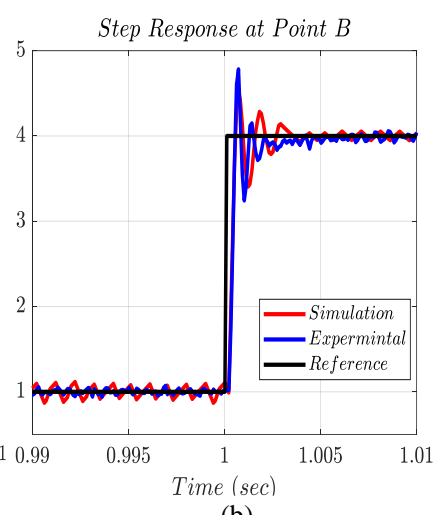

(b)
Fig. 24 Results of current step responcse at points A and B

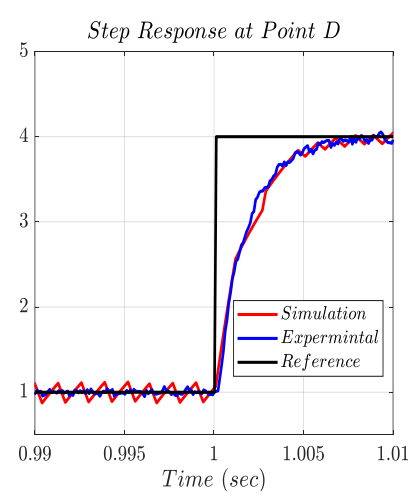

(a)

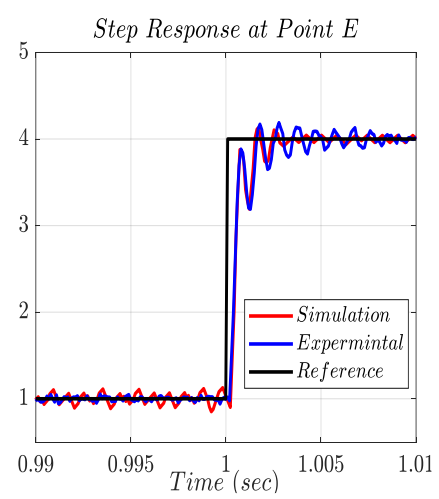

(b)
Fig. 25 Results of current step responcse at points D and E 


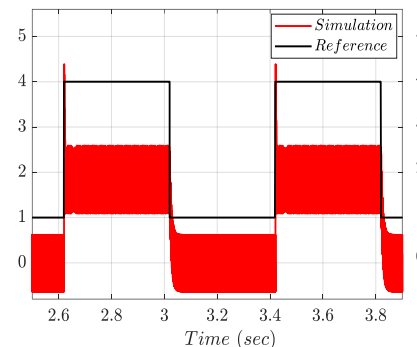

(a)Simulation at point $\mathrm{C}$

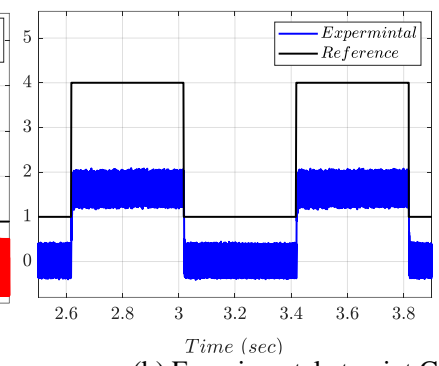

(b) Experimental at point $\mathrm{C}$
Fig. 26 Results of current step responcse at point $\mathrm{C}$

These results prove the analytical finding of previous Sections and demonstrate the effectiveness of the proposed method of ADRC CC design and analysis. The results also validate the proposed stability map for selecting the gains of ADR CC to avoid the instability and guarantee the dynamic performance of the drive system.

\section{Robustness during Uncertainties}

As studied in Section VI, the CC stability degrades when the machine inductance decreases, or the inductance value used for the controller design is larger than the actual machine inductance.

These effects can be analyzed experimentally by setting the inductance in the controller $L^{\prime}$ to be higher than the nominal value $L$ mentioned in Table III. This condition simulates the reduction in the machine inductance due to the saturation and cross saturation effects. Accordingly, the results have been measured using the controller setting of point $\mathrm{A}$ as shown in Fig. 27a when inductance value used in the controller equals to $1.35 \mathrm{pu}$. Compared to the results in Fig. 24.a, the results show the degradation in the system stability as expected from studying the eigenvalues migration shown in Section VI.

According to the outcomes of Section VII, setting the inductance value in the controller $L^{\prime} 0.6 \ldots 0.7 \mathrm{pu}$ enhances the system performance and provides more stable responses. These analytical findings are validated by the results in Fig. 27.b where $L^{\prime}$ is set at $0.65 p u$ for point B: it is clearly seen that the system provides more stable response, hence enlarging the stable region. In other words, such tuning improves the system robustness with respect to the machine inductance variation. These tendencies fully comply with the outcomes of the

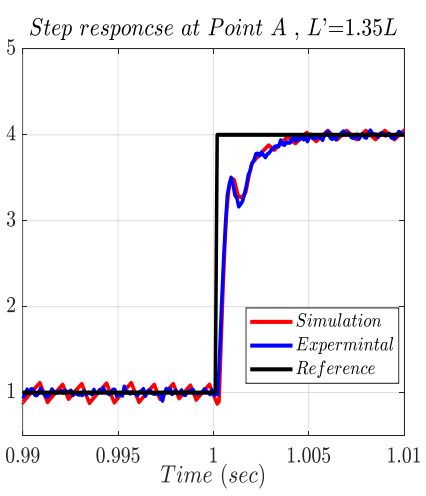

(a)

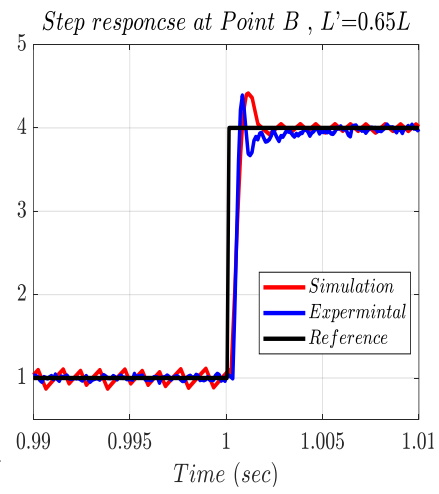

(b)
Fig. 27 Results of current step responcse at points A and B at different inductance sets analytical studies reported Sections VI and VII when migration of the eigenvalues has been investigated.

\section{CONCLUSION}

The current controller design based on active disturbance rejection control has been addressed and analyzed. Compared to previous works in this area, the proposed method takes into account the existence of system time delays, as well as ESO dynamics in order to improve performance of ADRC CC type. From stability analysis it has been shown that the time delay imposes limits for both the ESO, and the feedback controller gains, and conventional $\mathrm{CC}$ tuning method may lead to unstability or severely degraded performances. Simple, and reliable design methodology is proposed for ADRC-based CCs in motor drives. A "stability map" approach is proposed to avoid the unstable gains sets and to guarantee the $\mathrm{CC}$ dynamic performance. In addition, the effect of the model uncertainties on the system stability and its robustness has been investigated and recommendations as for $\mathrm{CC}$ tuning are given. The key analytical results have been successfully confirmed by both the detailed time-domain simulations and the experimental results. The proposed design method for ADRC CC in motor drives give a good insight to the system behavior, as well as very simple, clear and easy to implement. Therefore, it can be applied to the PMSM drives for applications where a high dynamic performance in harsh conditions is essential.

\section{APPENDIX}

The generic expression of the closed loop poles of equation (30) can be as follows

$$
\begin{gathered}
p_{c l 1,2} \cong \frac{1}{6}\left\{\begin{array}{c}
{\left[-t^{2}-2 t\left(K_{p}+4 f_{s w}\right)-t^{3}\left(K_{p}^{2}-20 f_{s w} K_{p}\right)\right] \mp} \\
j\left[\sqrt{3} t^{2}-t^{3}\left(K_{p}^{2}-20 f_{s w} K_{p}\right)\right]
\end{array}\right\} \\
p_{c l 3}=\frac{t}{3}\left[t-\left(K_{p}+4 f_{s w}\right)+t^{2}\left(K_{p}{ }^{2}+20 f_{s w} K_{p}\right)\right]
\end{gathered}
$$

where,

$t=2 f_{s w} \sqrt{\alpha}-K_{p}{ }^{3}-30 f_{s w} K_{p}{ }^{2}-168 f_{s w}{ }^{2} K_{p}+32 f_{s w}{ }^{3}$

$\alpha=9 K_{p}{ }^{4}+504 f_{s w} K_{p}{ }^{3}+6576 f_{s w}{ }^{2} K_{p}{ }^{2}-2688 f_{s w}{ }^{3} K_{p}+256 f_{s w}{ }^{4}$

\section{REFERENCES}

[1] B. Lequesne, "Automotive Electrification: The Nonhybrid Story," IEEE Transactions on Transportation Electrification, vol. 1, no. 1, pp. 40-53, 2015.

[2] P. Wheeler and S. Bozhko, "The More Electric Aircraft: Technology and challenges," IEEE Electrification Magazine, vol. 2, no. 4, pp. 6-12, 2014.

[3] P. Giangrande et al., "Considerations on the Development of an Electric Drive for a Secondary Flight Control Electromechanical Actuator," IEEE Transactions on Industry Applications, vol. 55, no. 4, pp. 3544-3554, 2019.

[4] S. Bozhko et al., "Development of Aircraft Electric Starter-Generator System Based on Active Rectification Technology," IEEE Transactions on Transportation Electrification, vol. 4, no. 4, pp. 985-996, 2018.

[5] D. Gerada, A. Mebarki, N. L. Brown, C. Gerada, A. Cavagnino, and A. Boglietti, "High-Speed Electrical Machines: Technologies, Trends, and Developments," IEEE Transactions on Industrial Electronics, vol. 61, no. 6, pp. 2946-2959, 2014.

[6] V. Madonna, A. Walker, P. Giangrande, G. Serra, C. Gerada, and M. Galea, "Improved Thermal Management and Analysis for Stator End- 
Windings of Electrical Machines," IEEE Transactions on Industrial Electronics, vol. 66, no. 7, pp. 5057-5069, 2019.

[7] C. Jong-Woo and S. Seung-Ki, "Fast current controller in three-phase AC/DC boost converter using d-q axis crosscoupling," IEEE Transactions on Power Electronics, vol. 13, no. 1, pp. 179-185, 1998.

[8] A. G. Yepes, A. Vidal, J. Malvar, O. López, and J. Doval-Gandoy, "Tuning Method Aimed at Optimized Settling Time and Overshoot for Synchronous Proportional-Integral Current Control in Electric Machines," IEEE Transactions on Power Electronics, vol. 29, no. 6, pp. 3041-3054, 2014.

[9] D. G. Holmes, B. P. McGrath, and S. G. Parker, "Current Regulation Strategies for Vector-Controlled Induction Motor Drives," IEEE Transactions on Industrial Electronics, vol. 59, no. 10, pp. 3680-3689, 2012.

[10] F. Briz and M. Hinkkanen, "Design, implementation and performance of synchronous current regulators for AC drives," Chinese Journal of Electrical Engineering, vol. 4, no. 3, pp. 53-65, 2018.

[11] J. Holtz, Q. Juntao, J. Pontt, J. Rodriguez, P. Newman, and H. Miranda, "Design of fast and robust current regulators for high-power drives based on complex state variables," IEEE Transactions on Industry Applications, vol. 40, no. 5, pp. 1388-1397, 2004.

[12] T. M. Rowan and R. J. Kerkman, "A New Synchronous Current Regulator and an Analysis of Current-Regulated PWM Inverters," IEEE Transactions on Industry Applications, vol. IA-22, no. 4, pp. 678-690, 1986.

[13] S. A. Odhano, P. Giangrande, R. Bojoi, and C. Gerada, "Selfcommissioning of interior permanent magnet synchronous motor drives with high-frequency current injection," in 2013 IEEE Energy Conversion Congress and Exposition, 2013, pp. 3852-3859.

[14] S. Li, B. Sarlioglu, S. Jurkovic, N. R. Patel, and P. Savagian, "Analysis of Temperature Effects on Performance of Interior Permanent Magnet Machines for High Variable Temperature Applications," IEEE Transactions on Industry Applications, vol. 53, no. 5, pp. 4923-4933, 2017.

[15] A. Diab, M. Rashed, J. Li, C. Gerada, and S. Bozhko, "Performance Analysis of PMSM for High-Speed Starter-Generator System," in 2018 IEEE International Conference on Electrical Systems for Aircraft, Railway, Ship Propulsion and Road Vehicles \& International Transportation Electrification Conference (ESARS-ITEC), 2018, pp. 17.

[16] M. D. Soricellis, D. D. Rù, and S. Bolognani, "A Robust Current Control Based on Proportional-Integral Observers for Permanent Magnet Synchronous Machines," IEEE Transactions on Industry Applications, vol. 54, no. 2, pp. 1437-1447, 2018.

[17] Y. I. Son, I. H. Kim, D. S. Choi, and H. Shim, "Robust Cascade Control of Electric Motor Drives Using Dual Reduced-Order PI Observer," IEEE Transactions on Industrial Electronics, vol. 62, no. 6, pp. 3672-3682, 2015.

[18] B. Guo, S. Bacha, and M. Alamir, "A review on ADRC based PMSM control designs," in IECON 2017 - 43rd Annual Conference of the IEEE Industrial Electronics Society, 2017, pp. 1747-1753.

[19] J. Han, "From PID to Active Disturbance Rejection Control," IEEE Transactions on Industrial Electronics, vol. 56, no. 3, pp. 900-906, 2009.

[20] X. Chang, Y. Li, W. Zhang, N. Wang, and W. Xue, "Active Disturbance Rejection Control for a Flywheel Energy Storage System," IEEE Transactions on Industrial Electronics, vol. 62, no. 2, pp. 991-1001, 2015.

[21] J. Yang, H. Cui, S. Li, and A. Zolotas, "Optimized Active Disturbance Rejection Control for DC-DC Buck Converters With Uncertainties Using a Reduced-Order GPI Observer," IEEE Transactions on Circuits and Systems I: Regular Papers, vol. 65, no. 2, pp. 832-841, 2018.

[22] S. Bosheng and G. Zhiqiang, "A DSP-based active disturbance rejection control design for a 1-kW H-bridge DC-DC power converter," IEEE Transactions on Industrial Electronics, vol. 52, no. 5, pp. 1271-1277, 2005.

[23] H. He, C. Zhang, and C. Wang, "Research on Active Disturbance Rejection Control of Induction Motor," in 2019 IEEE 4th Advanced Information Technology, Electronic and Automation Control Conference (IAEAC), 2019, vol. 1, pp. 1167-1171.

[24] X. Gan, C. Liu, K. Wang, Y. Hu, and Y. Zuo, "Active Disturbance Rejection Controller for PMSM Current Loop Based on Improvement of Time Delay," in 2016 IEEE Vehicle Power and Propulsion Conference (VPPC), 2016, pp. 1-5.
[25] H. Wu and J. Huang, "Control of Induction Motor Drive based on ADRC and Inertia Estimation," in 2019 IEEE International Electric Machines \& Drives Conference (IEMDC), 2019, pp. 1607-1612.

[26] G. U. O. B, B. S, A. M, and H. Iman-Eini, "A Robust LESO-based DCLink Voltage Controller for Variable Speed Hydro-Electric Plants," in 2019 IEEE International Conference on Industrial Technology (ICIT), 2019, pp. 361-366.

[27] W. Tan and F. Caifen, "Analysis of active disturbance rejection control for processes with time delay," in 2015 American Control Conference (ACC), 2015, pp. 3962-3967.

[28] W. Tan and C. Fu, "Linear Active Disturbance-Rejection Control: Analysis and Tuning via IMC," IEEE Transactions on Industrial Electronics, vol. 63, no. 4, pp. 2350-2359, 2016.

[29] B. Ahi and M. Haeri, "Linear Active Disturbance Rejection Control From the Practical Aspects," IEEE/ASME Transactions on Mechatronics, vol. 23, no. 6, pp. 2909-2919, 2018.

[30] G. Herbst, "Practical Active Disturbance Rejection Control: Bumpless Transfer, Rate Limitation, and Incremental Algorithm," IEEE Transactions on Industrial Electronics, vol. 63, no. 3, pp. 1754-1762, 2016.

[31] G. Herbst, "A Simulative Study on Active Disturbance Rejection Control (ADRC) as a Control Tool for Practitioners," Electronics, vol. 2, no. 3, pp. 246-279, 2013.

[32] G. Zhiqiang, "Scaling and bandwidth-parameterization based controller tuning," in Proceedings of the 2003 American Control Conference, 2003., 2003, vol. 6, pp. 4989-4996.

[33] M. F. Golnaraghi, Automatic control systems, 9th ed. / Farid Golnaraghi, Benjamin C. Kuo. ed. Hoboken, N.J.: Hoboken, N.J. : Wiley, 2010.

[34] Y. Zhang, Y. Xue, D. Li, Z. Gao, H. Niu, and H. Huang, "Frequency response analysis on modified plant of extended state observer," in 2017 17th International Conference on Control, Automation and Systems (ICCAS), 2017, pp. 1237-1241.

[35] B. Bon-Ho and S. Seung-Ki, "A compensation method for time delay of full-digital synchronous frame current regulator of PWM AC drives," IEEE Transactions on Industry Applications, vol. 39, no. 3, pp. 802-810, 2003.

[36] C. H. V. D. Broeck, S. A. Richter, J. V. Bloh, and R. W. D. Doncker, "Methodology for analysis and design of discrete time current controllers for three-phase PWM converters," CPSS Transactions on Power Electronics and Applications, vol. 3, no. 3, pp. 254-264, 2018.

[37] D. G. Holmes, T. A. Lipo, B. P. McGrath, and W. Y. Kong, "Optimized Design of Stationary Frame Three Phase AC Current Regulators," IEEE Transactions on Power Electronics, vol. 24, no. 11, pp. 2417-2426, 2009.

[38] B. C. Kuo, Automatic control system / Benjamin C. Kuo (no. Accessed from https://nla.gov.au/nla.cat-vn2546847). London: Prentice-Hall International, 1962.

[39] C. Choi, W. Lee, S. Kwon, and J. Hong, "Experimental Estimation of Inductance for Interior Permanent Magnet Synchronous Machine Considering Temperature Distribution," IEEE Transactions on Magnetics, vol. 49, no. 6, pp. 2990-2996, 2013.

[40] J. Im, W. Kim, K. Kim, C. Jin, J. Choi, and J. Lee, "Inductance Calculation Method of Synchronous Reluctance Motor Including Iron Loss and Cross Magnetic Saturation," IEEE Transactions on Magnetics, vol. 45, no. 6, pp. 2803-2806, 2009. 


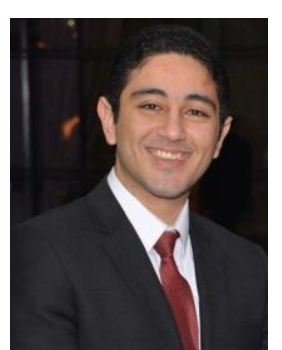

Ahmed M. Diab received the B.Sc. (Hons.) and M.Sc. degrees from Zagazig University, Zagazig, Egypt in 2011 and 2016, respectively. He is currently working toward the Ph.D. degree at the University of Nottingham Ningbo China and Institute for Aerospace technology (IAT), university of Nottingham, Nottingham, UK. From 2011 to 2016, he was a research and Teaching Assistant with the Department of Electrical Power and Machines, Zagazig University. His research interests include modeling, control, and stability in high speed Motor/generator systems for transportation electrification applications and in variable-speed wind generators.

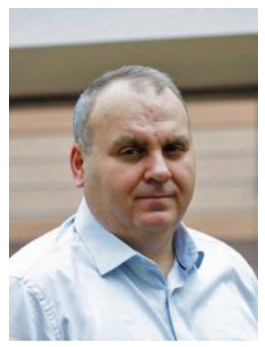

Serhiy Bozhko (M'96-SM'18) received the M.Sc. and Ph.D. degrees in electromechanical systems from the National Technical University of Ukraine, Kyiv, Ukraine, in 1987 and 1994, respectively. Since 2000, he has been with the Power Electronics, Machines and Controls Research Group, University of Nottingham, Nottingham, U.K., where he is currently a Professor of Aircraft Electric Power Systems. He is leading several EU- and industry-funded projects in the area of electric power systems for aerospace, including power generation, distribution, and conversion, power quality, control and stability issues, power management and optimization, as well as advanced modeling and simulations methods.

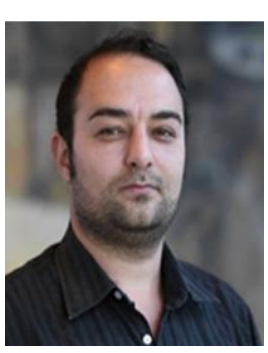

Michael Galea (M'13-SM'18) received the Ph.D. degree in electrical machines design from the University of Nottingham, Nottingham, U.K., in 2013. He was appointed as Lecturer in 2014, as an Associate Professor in 2018 and as a Professor in Electrical Machines and Drives in 2019, all with the University of Nottingham. He is currently the Head of the School of Aerospace, University of Nottingham Ningbo China, where he is also the Director of Aerospace. He currently lectures in Electrical Machines and Drives and in Aerospace Systems Integration and manages a number of diverse projects and programs related to the more/all electric aircraft, electrified propulsion, and associated fields. His main research interests include design and development of electrical machines and drives (classical and unconventional), reliability and lifetime degradation of electrical machines, and the more electric aircraft. Dr. Galea is a Fellow of the Royal Aeronautical Society and is on the Executive Board of the U.K. Magnetics Society.

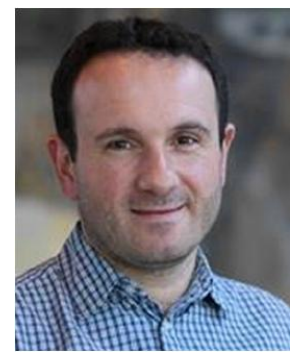

Chris Gerada (M'05-SM'12) received the Ph.D. degree in numerical modeling of electrical machines from the University of Nottingham, Nottingham, U.K., in 2005. He subsequently worked as a Researcher with the University of Nottingham on high performance electrical drives and on the design and modeling of electromagnetic actuators for aerospace applications. In 2008, he was appointed as a Lecturer in Electrical Machines; in 2011, as an Associate Professor; and in 2013, as a Professor with the University of Nottingham. His main research interests include the design and modeling of high-performance electric drives and machines. Dr. Gerada serves as an Associate Editor for the IEEE TRANSACTIONS ON INDUSTRY APPLICATIONS and is the past Chair of the IEEE IES Electrical Machines Committee. He was awarded a Research Chair from the Royal Academy of Engineering in 2013 